\title{
Are caveolin-1 minor alleles more likely to be risk alleles in insulin resistance mechanisms in metabolic diseases?
}

\author{
Faezeh Abaj ${ }^{1}$, Said Abdul Ghafour Saeedy ${ }^{2}$ and Khadijeh Mirzaei ${ }^{{ }^{*}}$ (D)
}

\begin{abstract}
Objectives: Obesity and insulin resistance (IR) are interrelated in a range of ways. The IR-obesity relationship is not a cause-and-effect association. Molecular biology research has made tremendous strides in discovering contributors to find this association. Genes that control adipocyte function such as caveolin-1 (CAV1); probably interact in the pathogenesis of human IR in this context. The involvement of CAVI in glucose/lipid homeostasis is revealed and could modify the signaling of the insulin receptor. We examined the association between CAV1 and insulin signaling in modifying dyslipidemia and fat composition in overweight and obese women with a prevalent variant in the CAV1 gene.

Results: Minor allele carriers were slightly older and had higher BMI $(p=0.02)$, FMI $(p=0.006)$, and VLF $(p=0.01)$ values; and tended to have lower total cholesterol TC $(p=0.04)$, low-density lipoprotein cholesterol (LDL-C) $(p=0.001)$ and high-density lipoprotein cholesterol (HDL-C) $(p=0.003)$. HOMA-IR levels predicted fat mass index (FMI) $0.47(0.08$, 0.87), visceral fat level (VFL) $0.65(0.23,1.07)$, TC $6.82(1.76,11.88)$ and HDL-C $-1.663(-3.11,-0.214)$ only between minor allele carriers in adjusted models. $(\beta, C I)$. Our results cast a new light on the IR mechanism and future studies will elucidate the clinical relevance of CAV1-IR in patients with dyslipidemia and high fat composition.
\end{abstract}

Keywords: Caveolin-1, Insulin resistance, Dyslipidemia, Polymorphism, Obesity

\section{Introduction}

Preceding studies have established the principal role of Insulin resistance (IR) and resultant hyperinsulinemia in cardiometabolic risk factors $[1,2]$. Inappropriate signaling of insulin has been associated with impaired fat distribution, adipocyte metabolism, and dyslipidemia [3]. According to studies, IR is associated with obesity, especially visceral obesity, hypercholesterolemia, hypertriglyceridemia, and low HDL-C concentration [4-7]. Obesity and IR are interrelated in various forms [8].

\footnotetext{
*Correspondence: mirzaei_kh@tums.ac.ir; mina_mirzaei101@yahoo.com ${ }^{1}$ Department of Community Nutrition, School of Nutritional Sciences and Dietetics, Tehran University of Medical Sciences (TUMS), No. 44, Hojjat-dost Alley, Naderi St., Keshavarz Blvd, P.O. Box, 14155-6117 Tehran, Iran

Full list of author information is available at the end of the article
}

Obesity-associated IR is the main risk factor for type 2 diabetes and cardiovascular disease $[9,10]$. Over the past years, a vast range of endocrine, inflammatory, neural, and cell-intrinsic paths have been revealed to be dysregulated in obesity. While it is likely that one of these factors plays a principal role, many of these factors are inter-reliant, and their interaction probably underlies the pathophysiology of IR [11]. Indeed, the relationship between obesity and IR is not possible a cause-and-effect relationship. Molecular biology research has made wonderful strides in discovering and defining many more contributors to find this relationship. The exact mechanisms for the insulin-induced defects including adipocyte dysfunction are unclear. However, several genomic and nongenomic pathways are present that mediate these IR effects. Furthermore, these effects could be secondary to

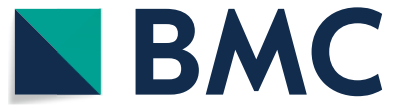

(c) The Author(s) 2021. This article is licensed under a Creative Commons Attribution 4.0 International License, which permits use, sharing, adaptation, distribution and reproduction in any medium or format, as long as you give appropriate credit to the original author(s) and the source, provide a link to the Creative Commons licence, and indicate if changes were made. The images or other third party material in this article are included in the article's Creative Commons licence, unless indicated otherwise in a credit line to the material. If material is not included in the article's Creative Commons licence and your intended use is not permitted by statutory regulation or exceeds the permitted use, you will need to obtain permission directly from the copyright holder. To view a copy of this licence, visit http://creativeco mmons.org/licenses/by/4.0/. The Creative Commons Public Domain Dedication waiver (http://creativecommons.org/publicdomain/ zero/1.0/) applies to the data made available in this article, unless otherwise stated in a credit line to the data. 
alternative plasma membrane proteins, and other receptors [12].

Caveolin-1 (CAV1), a 21-24 kDa integral membrane protein, is the main structural protein of caveolae. The location of the CAV1 gene is on human chromosome 7 (7q31.1) and it contains 3 exons that select intronic SNPs. CAV1 acts as scaffolding and has been involved in transmembrane signaling [13]. CAV1 is an important constituent of the lipid raft that controls their activity and cooperates with several signaling pathways, involving steroid receptors [14]. Rs3807992 is a mutation located in intron 2 of the CAV1 with the substitute of A to G. The functional study at the mRNA and protein levels for the function of CAV1(3807992) is still deficient. In literature, the source of most of the evidence is from studies in other SNPs in this gene. For example, the minor CAV1 rs926198 allele is linked with lower CAV1 expression levels [15]. Two common polymorphisms in the CAV1 gene are rs3807989 and rs1049334, and both of them are described to be considerably coupled with elevated expression of CAV1 mRNA and protein [16, 17]. The association between metabolic disease and CAV1 deficiency has been studied mainly in animal models. CAV1 knockout mice display numerous metabolic defects, including hyperglycemia, IR, and dyslipidemia, like those seen in humans with severe, nonsense CAV1 mutations [18-20]. As has been explored in preceding studies, $C A V 1$ gene variants were correlated with IR, dyslipidemia, diabetes mellitus, and metabolic syndrome [21].

The main location of the insulin receptor of the adipocyte is suggested to be in caveolae and bound to immobilized caveolin to excites their signaling [22]. The clinical significance of the relationship between CAV1 and IRmediated mechanisms in adipose tissue in the pathogenesis of IR in humans has been discussed. Here, we talk about the hypothesis that the CAV1-IR mechanism is a mediator of cardiometabolic disorder in caveolin genotypes.

Despite the developing knowledge in understanding the role of insulin pathways in dyslipidemia, to date no study has considered whether this mechanism works the same in all participants; and whether minor alleles are more likely to be risk alleles in IR mechanisms in metabolic diseases or not. We investigated the potential interplay between IR levels and a selected human $C A V 1$ gene variant (rs3807992) in modulating dyslipidemia and body fat composition.

\section{Main text \\ Method \\ Subjects}

For this cross-sectional study, we analyzed the data which was collected from samples of Tehranian overweight/ obese females, aged over 18 and were before menopause. Women with a history of chronic and inflammatory disease and who were pregnant or lactating, taking any therapeutic medications, or follow a special diet or supplements were excluded. After the final exclusion, 404 women remained in the present analysis. The study participants were fully informed concerning the research protocol and they signed a consent form before taking part in the research. Tehran University of medical sciences (TUMS) ethics committee agreed with these protocols (97-03-161-41017).

\section{Procedures}

Anthropometric variables were measured by standard protocols. We used digital scales for measuring weight, and measuring tape for measurement of height and waist circumference while the subjects were standing with bare feet. Body mass index (BMI) was calculated as a ratio of weight $(\mathrm{kg})$ to height in meters squared. Bioelectrical impedance analysis [BIA 770 (South Korea)] is an electrical method of assessing human body composition and was used to assess the VFL, body fat mass (BFM), and FMI. International Physical Activity Questionnaires (IPAQ) were used to assess physical activity [23]. A Food Frequency Questionnaire (FFQ) was used to calculate energy intake.

\section{Genotyping}

The Mini Columns kit (Type G; Genall; Exgene) was used for DNA extraction. The CAV1 SNP (rs3807992) was genotyped by PCR-RFLP method, using primers, Forward: 3'AGTATTGACCTGATTTGCCATG5' Reverse: $5^{\prime}$ GTCTTCTGGAAAAAGCACATGA-3' ${ }^{\prime}$. According to our previous study [24].

\section{Measurements of biochemical parameters}

We collected blood samples after 10-12 h of overnight fasting. For measurement of FPG, glucose oxidase phenol 4-aminoantipyrine peroxidase (GOD/PAP) method was used [25]. Furthermore, triacylglycerol kits (Pars Azmoon Inc, Tehran, Iran) were applied for the determination of serum TG level. The total TC level was evaluated by the cholesterol oxidase phenol 4-aminoantipyrine peroxidase (CHOD-PAP) method [26]. Besides, highdensity lipoprotein (HDL) and low-density lipoprotein (LDL) were measured by the direct method and immunoinhibition [27].

\section{HOMA-IR calculation}

Homeostatic model assessment (HOMA) calculated by using this formula: HOMA-IR $=1 / 4[\mathrm{FPG}(\mathrm{mmol} / \mathrm{l}) \times$ fasting plasma insulin $(\mathrm{mIU} / \mathrm{l})] / 22.5[28]$. 


\section{Statistical analysis}

IBM SPSS statistics (version 25) was used for all phases of the analysis (SPSS Inc, Chicago, IL, USA). The evaluation of the normality of quantitative variables was conducted by K-S (Kolmogorov-Smirnov) test. Independent Student's $t$-test was used to baseline analysis comparing by genotype status. The adjusted linear regression model was used to assess the relationship between HOMA-IR levels and cardiometabolic variables, first, in all participants without grouping; and subsequently in whom that were grouped by rs387992 genotype status adjusted for age, energy intake, and IPAC index. Data are presented as means $\pm \mathrm{SD}$, and $P<0.05$ is considered statistically significant.

\section{Results}

\section{Study population}

A total of 404 adults were analyzed. Our study had the following characteristics: age $36.67 \pm 9.1$ years, body mass index $\left(\mathrm{kg} / \mathrm{m}^{2}\right)$ of $31.26 \pm 4.2$. Using a dominant model for genetic analysis, a homozygous major allele (GG) of the rs3807992 CAV1 variant was observed in $50 \%$ of participants, and the other $50 \%$ were minor allele carriers $(23.31 \%$ had an AG genotype and $26.6 \%$ had an AA genotype).

\section{Clinical and biochemical characteristics categorized by CAV1 genotype:}

Compared with those with the homozygous major allele of rs3807992 CAV1 variant, minor allele carriers had no statistical differences $(p>0.05)$ in FPG, plasma insulin, and HOMA-IR, as are described in Table 1. Minor allele carriers were slightly older $(p=0.05)$ and had higher BMI $(p=0.02)$, FMI $(p=0.006), \operatorname{VLF}(p=0.01)$ values, and tended to have lower TC $(p=0.04)$, LDL-C $(p=0.001)$, and HDL-C levels $(p=0.003)$ (Fig. 1).

\section{The CAV1 variant modulates the effect of HOMA-IR on lipid hemostasis and lipid profile}

A statistically significant relationship was found between $C A V 1$ variants and anthropometric data and lipid profile values. Since rs387992 genotype and HOMA-IR levels were associated with anthropometric data and lipid profile values, we considered whether they were independent predictors in a linear regression model or not.

As shown in Table 2, we found both rs3807992 status and HOMA-IR levels significant predictors of lipid profiles and anthropometric status with a statistically significant interaction. To further analyze the relationship between these predictors, we stratified the effect of HOMA-IR on TC by genotype. Interestingly, HOMA-IR levels predicted TC between all participant 5.32 (153.65,
Table 1 Clinical and biochemical characteristics categorized by Cav-1 variant rs3807992

\begin{tabular}{|c|c|c|c|}
\hline Variable & $\begin{array}{l}\text { Minor allele carrier } \\
\text { AA/AG }\end{array}$ & $\begin{array}{l}\text { Major allele carrier } \\
\text { GG }\end{array}$ & P-value* \\
\hline Age & $35.75 \pm 8.78$ & $37.56 \pm 9.49$ & 0.05 \\
\hline BMI & $31.66 \pm 4.46$ & $30.68 \pm 4.01$ & 0.02 \\
\hline FMI & $3.46 \pm 13.83$ & $3.25 \pm 12.93$ & 0.006 \\
\hline VFL & $3.11 \pm 16.28$ & $3.40 \pm 15.46$ & 0.01 \\
\hline FBS & $86.95 \pm 9.75$ & $87.98 \pm 9.62$ & 0.31 \\
\hline Insulin & $1.22 \pm 0.25$ & $1.21 \pm 0.22$ & 0.61 \\
\hline HOMA-IR & $3.53 \pm 1.82$ & $3.27 \pm 1.21$ & 0.54 \\
\hline TG & $133.31 \pm 84.14$ & $113.11 \pm 51.20$ & 0.14 \\
\hline $\mathrm{HDL}$ & $44.04 \pm 10.16$ & $49.07 \pm 11.16$ & 0.003 \\
\hline LDL & $91.27 \pm 25.07$ & $98.80 \pm 22.66$ & 0.001 \\
\hline TC & $182.71 \pm 37.36$ & $186.76 \pm 33.74$ & 0.04 \\
\hline
\end{tabular}

A significant $P$-values are indicated in bold (significance considered $P<0.05$ )

Values are mean (SD)

*Adjusted model by age, energy intake, IPAC and BMI

178.56) $(p=0.003)$ and only in minor allele carriers 6.82 $(1.76,11.88)(p=0.009)$ in adjusted models. Also, lower HDL-C levels were associated with HOMA-IR levels in all participants-1.473 $(-2.52,-0.42)(p=0.006)$. Moreover, these results were driven by the effect on minor allele carriers of the $C A V 1$ gene variant. There was a consistent significant interaction when analyzing HOMA-IR levels with rs3807992 genotypes predicting HDL-C levels $-1.663(-3.11,-0.214)(p=0.02)$.

We assessed whether changes in HOMA-IR levels predicted changes in VLF and FMI levels. Indeed, HOMAIR predicted higher VLF between all participants 0.51 $(0.19,0.83)(p=0.002)$ and in CAV1 minor allele carriers $0.65(0.23,1.07)(p=0.003)$ but not in major allele homozygotes. Moreover, higher FMI levels were associated with HOMA-IR levels in adjusted models in all participants $0.449(0.17,0.72)(P=0.002)$, but again, these results were driven by the effect on minor allele carriers of the $C A V 1$ gene variant $0.47(0.08,0.87)(P=0.01)$ but not in major allele homozygotes. In contrast, HOMA-IR levels were not associated with TG and LDL-C, because they were similar in both $C A V 1$ genotype groups.

\section{Discussion}

The unfolding story of caveolae and caveolin signaling in human health has started in the past. Our study has shown that the insulin pathway mediates some of the metabolic characteristics associated with defective caveolin genotype. Although HOMA-IR levels were similar in both carriers and non-carriers of the CAV1 minor allele, this study showed that HOMA-IR significantly estimates changes in TC, HDL-C, VLF, and FMI levels only in 

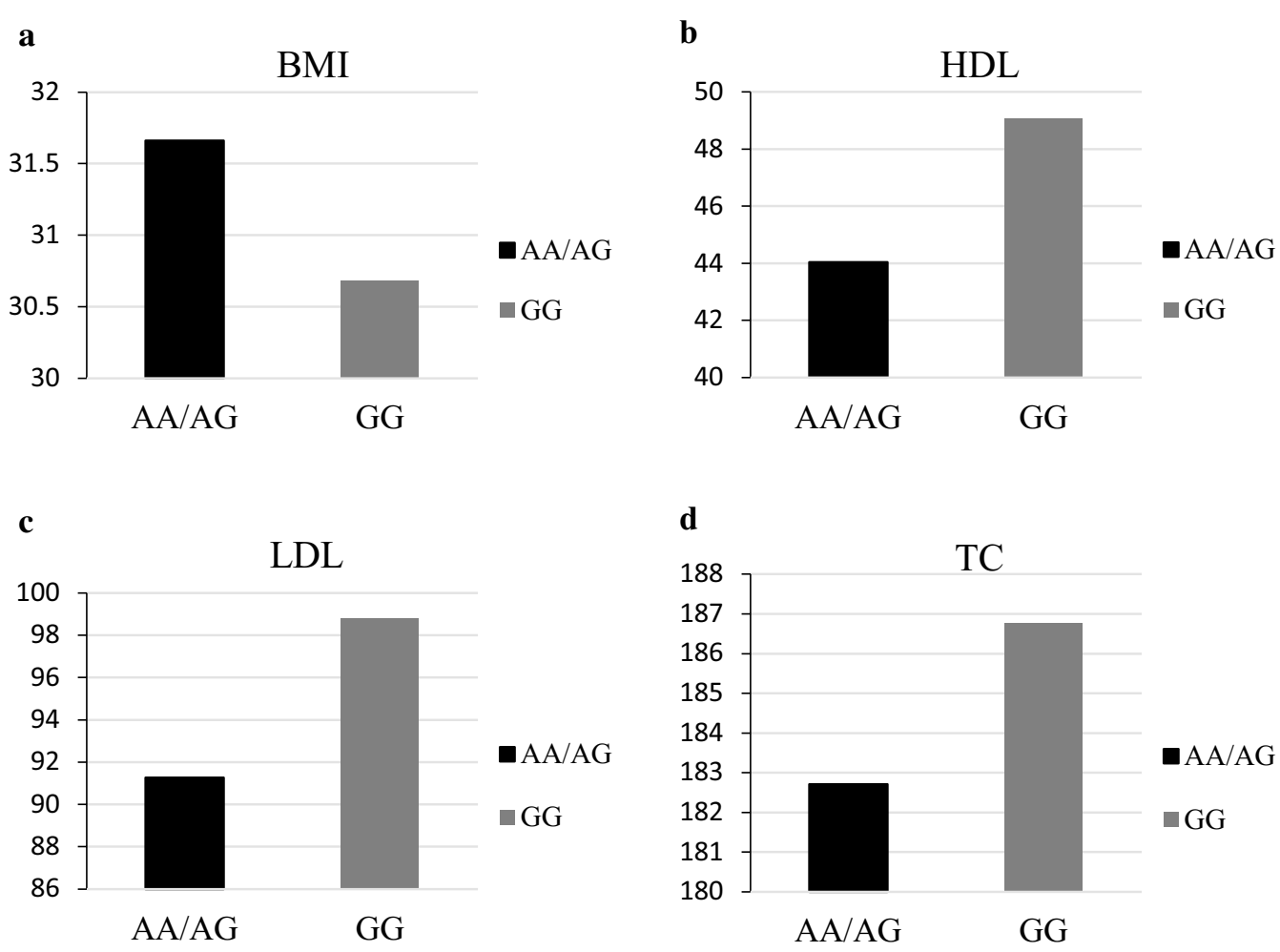

Fig. 1 Clinical and biochemical characteristics categorized by Cav-1 variant rs3807992. a BMI. b HDL. c LDL. d TC

minor allele carriers of $C A V 1$ gene variant. The different effect of HOMA-IR on VLF, FMI, HDL-C, and TC levels in minor allele carriers may be attributed to an insulin signaling defect predicted by $C A V 1$ genotype status. The relationship between TG and HOMA-IR seems to indicate that the effects of $C A V 1$ on TG are IR independent.

The relationship of HOMA-IR levels activation with higher TC, lower HDL-C, and alteration in lipid composition in participants is supported by different studies $[7,12,29-31]$. IR is related to CVD and T2DM risk factors, such as dyslipidemia and obesity (mainly visceral obesity). Obesity-IR association has been investigated previously, some studies suggested obesity as the cause of IR since human and animal studies show that weight loss/gain correlates closely with increasing/decreasing insulin sensitivity, respectively [32-34]. In contrast, several epidemiologic studies have found that one-third of obese individuals fall into the category of "metabolically healthy obese", they have additional body fat but no metabolic disruptions that describe the symptoms of IR [35]. In terms of this hypothesis, some studies of healthy people nourished with controlled high- and lowfat diets have shown that low-fat diets cause noteworthy improvements in whole-body insulin sensitivity [36-40]. In all these interventions, body weight was maintained unchanged; thus, corrections in insulin sensitivity on low-fat diets were not described by variations in weight. Though practically, obesity may obscure the association between fat consumption and IR. Clinical trials reveal that excessive levels of dietary fat can worsen insulin sensitivity independent of body weight variations [41]. On the other side, some researchers have suggested that IR is a "defense mechanism" of obese people against further weight gain [41].

There are two portal systems in the body: hypothalamus-pituitary and pancreas-liver. If the problem starts in the liver, then the pancreas has to secrete more insulin by mass action to make the liver do its job; this raises insulin levels all over the body, promotes adipogenesis, and generates peripheral IR all at the same time. Instead, if the IR starts first in the hypothalamus, the leptin signal is also antagonized there, causes increased appetite and weight gain and finally peripheral IR [42, 43]. Experimental studies indicate that it is a 2-way street. At first, IR can develop in the liver or central nervous system. But unfortunately, it is not possible to determine the location of this onset. Following the onset of IR in one of these two areas, hyperinsulinemia develops, followed by obesity and eventually IR in a vicious cycle [41]. For the reasons mentioned above, an understanding of the molecular 
Table 2 Adjusted linear regression models assessing the relationship between HOMA-IR levels and cardiometabolic variables in all participants by rs387992 genotype status

\begin{tabular}{|c|c|c|}
\hline $\begin{array}{l}\text { Cardiometabolic } \\
\text { variable }\end{array}$ & Category $^{a}$ & $\begin{array}{l}\text { HOMA-IR } \\
\text { Adjusted b }{ }^{\mathrm{b}}(95 \% \mathrm{Cl}) \\
\text { P value }\end{array}$ \\
\hline \multirow[t]{3}{*}{ FMI } & All participants & $\begin{array}{l}0.449(0.17,0.72) \\
\mathbf{P}=\mathbf{0 . 0 0 2}\end{array}$ \\
\hline & Minor allele carriers & $\begin{array}{l}0.47(0.08,0.87) \\
\mathbf{P}=\mathbf{0 . 0 1}\end{array}$ \\
\hline & Major allele homozygous & $\begin{array}{l}0.37(-0.037,0.77) \\
P=0.07\end{array}$ \\
\hline \multirow[t]{3}{*}{ VFL } & All participants & $\begin{array}{l}0.51(0.19,0.83) \\
\mathbf{P}=\mathbf{0 . 0 0 2}\end{array}$ \\
\hline & Minor allele carriers & $\begin{array}{l}0.65(0.23,1.07) \\
\mathbf{P}=\mathbf{0 . 0 0 3}\end{array}$ \\
\hline & Major allele homozygous & $\begin{array}{l}0.32(-0.18,0.83) \\
P=0.21\end{array}$ \\
\hline \multirow[t]{3}{*}{ TG } & All participants & $\begin{array}{l}15.25(10.88,21.63) \\
P \leq 0.0001\end{array}$ \\
\hline & Minor allele carriers & $\begin{array}{l}17.21(8.55,25.88) \\
P \leq 0.0001\end{array}$ \\
\hline & Major allele homozygous & $\begin{array}{l}17.6(10.40,24.81) \\
P \leq 0.0001\end{array}$ \\
\hline \multirow[t]{3}{*}{$\mathrm{HDL}$} & All participants & $\begin{array}{l}-1.473(-2.52,-0.42) \\
P=\mathbf{0 . 0 0 6}\end{array}$ \\
\hline & Minor allele carriers & $\begin{array}{l}-1.663(-3.11,-0.214) \\
P=\mathbf{0 . 0 2}\end{array}$ \\
\hline & Major allele homozygous & $\begin{array}{l}-0.87(-2.5,0.75) \\
P=0.29\end{array}$ \\
\hline \multirow[t]{3}{*}{ LDL } & All participants & $\begin{array}{l}1.64(-0.72,4.01) \\
P=0.17\end{array}$ \\
\hline & Minor allele carriers & $\begin{array}{l}2.47(-0.095,5.9) \\
P=0.15\end{array}$ \\
\hline & Major allele homozygous & $\begin{array}{l}1.13(-2.27,4.54) \\
P=0.51\end{array}$ \\
\hline \multirow[t]{3}{*}{ TC } & All participants & $\begin{array}{l}5.32(153.65,178.56) \\
P=\mathbf{0 . 0 0 3}\end{array}$ \\
\hline & Minor allele carriers & $\begin{array}{l}6.82(1.76,11.88) \\
\mathbf{P}=\mathbf{0 . 0 0 9}\end{array}$ \\
\hline & Major allele homozygous & $\begin{array}{l}3.88(-1.18,8.95) \\
P=0.13\end{array}$ \\
\hline
\end{tabular}

A significant $P$-values are indicated in bold (significance considered $P<0.05$ HOMA-IR indicates homeostasis model assessment of insulin resistance

${ }^{a}$ Categorized by Caveolin 1 genotype rs926198

${ }^{\mathrm{b}}$ Linear regression adjusted by age, energy intake, physical activity level

mechanism that causes IR is essential, and this information plays a significant role in counteracting the epidemic of type 2 diabetes and cardiovascular diseases that are associated with obesity-related IR.

Strong evidence is provided by early familial genetic studies to prove a genetic basis for both IR and the different constituents of the metabolic syndrome [44-50]. The major part of caveolae is CAV1, which has been revealed to lead to IR and cardiometabolic disease [51].
In pancreatic $\beta$-cells, CAV1 plays a role in insulin receptor-mediated signaling, insulin secretion, and probably in diabetes. In physiological low glucose circumstances, CAV1 forms a complex with insulin granule proteins, glucose stimulus mediates CAV1 dissociation and complex disassembly and promotes insulin secretion [52]. On the other side, different evidence indicates a vital role of caveolae in regulating not only insulin secretion but also insulin signaling [53]. Structural studies revealed that in the cell membrane, the insulin receptor is primarily localized in caveolae and only very few receptors are localized outside of caveolae [22]. Impairment of insulin receptor signaling in $\beta$ cells of the pancreas is observed in either cholesterol depletion or by a mutation that produces a dominant-negative CAV1. This issue again highlights the principal role of $C A V 1$ for the appropriate insulin response.

Moreover, the G32124A (rs3807992) polymorphism is located at the intronic region of the CAV1 gene. The variation of G32124A intronic polymorphism from CAV1 may alter the normal expression or protein function of the $C A V 1$ gene by regulating mRNA [54]. In the CAVI genotype, body fat distribution and dyslipidemia are suggested to be caused via the probable mechanism of disruption in insulin signaling [55]. The expression of the $C A V 1$ gene, in the adipose tissue of obese women who have more fat storage, is greater compared to lean people who have less fat storage [56]. For this reason, we hypothesized that the observed phenotype in minor allele carriers may be manipulated by disruption of insulin receptor function, at least in theory.

A probable role for $C A V 1$ in metabolic diseases is shown by animal studies and has indicated that CAV1deficient mice exhibit variations in lipid parameters including TC and HDL-C [57]. Moreover, human studies on nonsense mutations show that severe $C A V 1$ mutations exhibit IR and dyslipidemia [51]. The key mediator of cholesterol homeostasis is CAV1, and the function of $C A V 1$ in HDL-C metabolism was confirmed by higher levels of plasma HDL-C in CAV1 deficiency [58]. The relationship of $C A V 1$ variant and dyslipidemia is established by genome-wide association studies (GWAS) that exhibit a link of $C A V 1$ gene proximal regions to low HDL-C level $[29,59,60]$. Regulation of insulin signaling in adipose tissue could be considered a potential mechanism by which $C A V 1$ possibly alters lipid metabolism. Insulin promotes lipogenesis and inhibits lipolysis, which finally could alter adipose tissue metabolism. IR is the consequence of obesity which is seen in CAV1 knock-out mice [61] and is consistent with the medical descriptions of overweight and obese subjects by showing decreased insulin sensitivity in adipose tissues. 
HOMA-IR levels are associated with lower HDL-C and higher TC, VLF, FMI levels only in minor allele carriers that possibly could be accompanying with altered CAV1 expression. Our results support the theory that the mechanistic findings in the animal study likely also be valid to humans [62].

To the best of our knowledge, this report is the first study showing that $C A V 1$ minor allele predicted an association between IR and dyslipidemia and body fat composition. Novel mechanisms such as IR that could be related to specific cardiometabolic disorder pathways associated with $C A V 1$ deficiency in the human study are explored by this work. Whereas the history of human genetic researches on caveolin is limited, this amount of research confirms a potential association between IR and $C A V 1$. Our data have significant clinical consequences. First, we determined a genetic marker that could be used to screen for metabolic disease risk. Second, our results support the hypothesis that CAV1 is an emerging pathway that IR in humans leads to cardiometabolic disease.

\section{Conclusion}

Based on the present findings, it could be hypothesized that CAV1 (rs3807992) may be associated with increased metabolic disease risk factors in overweight and obese women. It appears that insulin pathways account for the association between $C A V 1$ rs3807992 and metabolic factors among minor allele carriers, and this could be critical for clinical diagnosis and gene therapy. Due to limited studies on the CAV1 polymorphism, more researches are warranted to evaluate the impacts of insulin pathways on caveolin-related metabolic disease.

\section{Limitations}

To the best of our knowledge, this was the first study to investigate the $C A V-1$ and IR-pathway with cardiometabolic factors, however, our study had several limitations such as having only overweight and obese women and because of financial limitation we could not perform western blot analysis. Besides, in our study the $C A V 1$ variant was assessed only in Iranian women, these findings may not be applicable for people of other races. In future studies, investigating samples from a greater geographic area might prove more important findings.

\section{Abbreviations}

BMI: Body mass index; FPG: Fasting plasma glucose; HDL-C: High-density lipoprotein cholesterol; LDL-C: Low-density lipoprotein cholesterol; RFLP: Restriction fragment length polymorphism; TC: Total cholesterol; TG: Triglyceride; FMI: Fat mass index; VFL: Visceral fat level; HOMA: Homeostatic model assessment.

\section{Acknowledgements}

The authors thank the participants in this research.

\section{Authors' contributions}

FA: conceptualization, methodology, investigation, formal analysis, and software; writing the original draft. SS; writing —review, and editing. KM: supervision, validation, and project administration. All authors have read and approved the manuscript.

\section{Funding}

This study was supported by a Grant from the Tehran University of Medical Sciences (41017). The funding agency played no role in the study design, data analysis, and interpretation, or in writing the manuscript. Sources of Support: Tehran University of Medical Science.

\section{Availability of data and materials}

The data are not publicly available due to containing private information of participants. Data are however available from the authors upon reasonable request and with permission of Khadijeh Mirzaei.

\section{Declarations}

Ethics approval and consent to participate

The protocol of the study was approved by the ethics committee of TUMS. All participants completed a written informed consent (IR.TUMS.VCR.REC 97-03-161-41017)

\section{Consent for publication}

Not applicable.

\section{Competing interests}

The authors declare that they have no competing interests.

\section{Author details}

${ }^{1}$ Department of Community Nutrition, School of Nutritional Sciences and Dietetics, Tehran University of Medical Sciences (TUMS), No. 44, Hojjat-dost Alley, Naderi St., Keshavarz Blvd, P.O. Box, 14155-6117 Tehran, Iran. ${ }^{2}$ Department of Paraclinic, School of Medicine, Herat University, Herat, Afghanistan.

Received: 25 December 2020 Accepted: 5 May 2021

Published online: 17 May 2021

\section{References}

1. Reaven GM. Banting lecture. Role of insulin resistance in human disease. Diabetes. 1988;1988(37):1595-607.

2. Ferrannini E, Muscelli E, Stern M, Haffner S. Differential impact of insulin and obesity on cardiovascular risk factors in non-diabetic subjects. Int J Obes Relat Metab Disord J Int Assoc Study Obes. 1996;20:7-14.

3. Karpe F, Dickmann JR, Frayn KN. Fatty acids, obesity, and insulin resistance: time for a reevaluation. Diabetes. 2011;60:2441-9.

4. Bampi ABA, Rochitte CE, Favarato D, Lemos PA, Luz PLd. Comparison of non-invasive methods for the detection of coronary atherosclerosis. Clinics. 2009;64:675-82.

5. Pineda-De Paz D, Pineda-De Paz M, Lee-Tsai Y, Chang C, Torres-Salazar L, Barrios C. Prevalencia de cardiopatía isquémica asintomática en pacientes con diabetes mellitus tipo 2. Rev Colomb Cardiol. 2017:25:116-23.

6. McLaughlin T, Reaven G, Abbasi F, Lamendola C, Saad M, Waters D, et al. Is there a simple way to identify insulin-resistant individuals at increased risk of cardiovascular disease? Am J Cardiol. 2005;96:399-404.

7. von Eckardstein A, Schulte H, Assmann G. Increased risk of myocardial infarction in men with both hypertriglyceridemia and elevated HDL cholesterol. Circulation. 1999;99:1925.

8. Uranga RM, Keller JN. The complex interactions between obesity. Metab Brain Front Neurosci. 2019;13:513.

9. Li Z, Bowerman S, Heber D. Health ramifications of the obesity epidemic. Surg Clin N Am. 2005;85:681-701.

10. Olshansky SJ. Projecting the future of U.S. health and longevity. Health Affairs (Project Hope). 2005;24(Suppl 2):W5r86-W5r9.

11. Qatanani M, Lazar MA. Mechanisms of obesity-associated insulin resistance: many choices on the menu. Genes Dev. 2007;21:1443-55. 
12. Ormazabal V, Nair S, Elfeky O, Aguayo C, Salomon C, Zuñiga FA. Association between insulin resistance and the development of cardiovascular disease. Cardiovasc Diabetol. 2018;17:122.

13. Razani B, Woodman SE, Lisanti MP. Caveolae: from cell biology to animal physiology. Pharmacol Rev. 2002;54:431-67.

14. Brown DA, London E. Functions of lipid rafts in biological membranes Annu Rev Cell Dev Biol. 1998;14:111-36.

15. Baudranda R. A prevalent caveolin-1 gene variant is associated with the metabolic syndrome in caucasians and hispanics. Metabolism. 2015;64:1674-81.

16. Zhao R, Liu K, Huang Z, Wang J, Pan Y, Huang Y, et al. Genetic variants in Caveolin-1 and RhoA/ROCK1 are associated with clear cell renal cell carcinoma risk in a Chinese population. PLOS ONE. 2015;10:e0128771.

17. Chen S, Wang X, Wang J, Zhao Y, Wang D, Tan C, et al. Genomic variant in CAV1 increases susceptibility to coronary artery disease and myocardial infarction. Atherosclerosis. 2016;246:148-56.

18. Chuengsamarn S, Garza AE, Krug AW, Romero JR, Adler GK, Williams GH, et al. Direct renin inhibition modulates insulin resistance in caveolin1-deficient mice. Metab Clin Exp. 2013;62:275-81.

19. Kim CA, Delépine M, Boutet E, El Mourabit H, Le Lay S, Meier M, et al. Association of a homozygous nonsense caveolin-1 mutation with Berardinelli-Seip congenital lipodystrophy. J Clin Endocrinol Metab. 2008;93:1129-34

20. Pojoga LH, Yao TM, Opsasnick LA, Garza AE, Reslan OM, Adler GK, et al. Dissociation of hyperglycemia from altered vascular contraction and relaxation mechanisms in caveolin-1 null mice. J Pharmacol Exp Ther. 2013;348:260-70

21. González-Muñoz E, López-Iglesias C, Calvo M, Palacín M, Zorzano A, Camps M. Caveolin-1 loss of function accelerates glucose transporter 4 and insulin receptor degradation in 3T3-L1 adipocytes. Endocrinology. 2009;150:3493-502

22. Gustavsson J, Parpal S, Karlsson M, Ramsing C, Thorn H, Borg M, et al. Localization of the insulin receptor in caveolae of adipocyte plasma membrane. Faseb J. 1999;13:1961-71.

23. Hagströmer M, Oja P, Sjöström M. The international physical activity questionnaire (IPAQ): a study of concurrent and construct validity. Public Health Nutr. 2006;9:755-62.

24. Abaj F, Saeedy SAG, Mirzaei K. Mediation role of body fat distribution (FD) on the relationship between CAV-1 rs3807992 polymorphism and metabolic syndrome in overweight and obese women. Res Square. 2020.

25. Purcell GV, Behenna DB, Walsh PR. Evaluation of the BMC glucose oxidase/peroxidase-4-aminophenazone-phenol procedure for glucose as adapted to the Technicon SMAC. Clin Chem. 1979;25:1844-6.

26. Wang SJ, Xu HZ, Xiao HL. Effect of high-frequency electroacupuncture on lipid metabolism in obesity rats. Zhen Ci Yan Jiu. 2008;33:154-8.

27. Miller WG, Myers GL, Sakurabayashi I, Bachmann LM, Caudill SP, Dziekonski A, et al. Seven direct methods for measuring HDL and LDL cholesterol compared with ultracentrifugation reference measurement procedures. Clin Chem. 2010;56:977-86.

28. Mirzaei K, Hossein-Nezhad A, Keshavarz SA, Eshaghi SM, Koohdani F, Saboor-Yaraghi AA, et al. Insulin resistance via modification of PGC1a function identifying a possible preventive role of vitamin D analogues in chronic inflammatory state of obesity. A double blind clinical trial study. Minerva Med. 2014;105:63-78.

29. Tam CH, Lam VK, So WY, Ma RC, Chan JC, Ng MC. Genome-wide linkage scan for factors of metabolic syndrome in a Chinese population. BMC Genet. 2010;11:14

30. Matthews D, Hosker J, Rudenski A, Naylor B, Treacher D, Turner R. Homeostasis model assessment: insulin resistance and $\beta$-cell function from fasting plasma glucose and insulin concentrations in man. Diabetologia. 1985;28:412-9.

31. Kahn SE, Hull RL, Utzschneider KM. Mechanisms linking obesity to insulin resistance and type 2 diabetes. Nature. 2006;444:840-6.

32. Bak JF, Møller N, Schmitz O, Saaek A, Pedersen O. In vivo insulin action and muscle glycogen synthase activity in Type 2 (non-insulin-dependent) diabetes mellitus: effects of diet treatment. Diabetologia. 1992;35:777-84.

33. Freidenberg GR, Reichart D, Olefsky JM, Henry RR. Reversibility of defective adipocyte insulin receptor kinase activity in non-insulin-dependent diabetes mellitus. Effect of weight loss. J Clin Investig. 1988;82:1398-406.
34. Sims EA, Danforth E Jr, Horton ES, Bray GA, Glennon JA, Salans LB. Endocrine and metabolic effects of experimental obesity in man. Recent Prog Horm Res. 1973;29:457-96.

35. Wildman RP, Muntner P, Reynolds K, McGinn AP, Rajpathak S, Wylie-Rosett $J$, et al. The obese without cardiometabolic risk factor clustering and the normal weight with cardiometabolic risk factor clustering: prevalence and correlates of 2 phenotypes among the US population (NHANES 1999-2004). Arch Intern Med. 2008;168:1617-24.

36. Chen M, Bergman RN, Porte D Jr. Insulin resistance and beta-cell dysfunction in aging: the importance of dietary carbohydrate. J Clin Endocrinol Metab. 1988;67:951-7.

37. Fukagawa NK, Anderson JW, Hageman G, Young VR, Minaker KL. Highcarbohydrate, high-fiber diets increase peripheral insulin sensitivity in healthy young and old adults. Am J Clin Nutr. 1990;52:524-8.

38. Lovejoy JC, Windhauser MM, Rood JC, de la Bretonne JA. Effect of a controlled high-fat versus low-fat diet on insulin sensitivity and leptin levels in African-American and Caucasian women. Metab Clin Exp. 1998:47:1520-4.

39. Straznicky NE, O'Callaghan CJ, Barrington VE, Louis WJ. Hypotensive effect of low-fat, high-carbohydrate diet can be independent of changes in plasma insulin concentrations. Hypertension (Dallas, Tex: 1979). 1999;1999(34):580-5.

40. Swinburn BA, Boyce VL, Bergman RN, Howard BV, Bogardus C. Deterioration in carbohydrate metabolism and lipoprotein changes induced by modern, high fat diet in Pima Indians and Caucasians. J Clin Endocrinol Metab. 1991;73:156-65.

41. <The Influence of Dietary fat.pdf>.

42. Brüning JC, Gautam D, Burks DJ, Gillette J, Schubert M, Orban PC, et al. Role of brain insulin receptor in control of body weight and reproduction. Science (New York, NY). 2000;289:2122-5.

43. Han JC, Rutledge MS, Kozlosky M, Salaita CG, Gustafson JK, Keil MF, et al. Insulin resistance, hyperinsulinemia, and energy intake in overweight children. J Pediatr. 2008;152(612-7):7.e1.

44. Sakul H, Pratley R, Cardon L, Ravussin E, Mott D, Bogardus C. Familiality of physical and metabolic characteristics that predict the development of non-insulin-dependent diabetes mellitus in Pima Indians. Am J Hum Genet. 1997;60:651.

45. Elbein SC, Hasstedt SJ, Wegner K, Kahn SE. Heritability of pancreatic $\beta$-cell function among nondiabetic members of Caucasian familial type 2 diabetic kindreds. J Clin Endocrinol Metab. 1999;84:1398-403.

46. Watanabe RM, Valle T, Hauser ER, Ghosh S, Eriksson J, Kohtamäki K, et al. Familiality of quantitative metabolic traits in Finnish families with noninsulin-dependent diabetes mellitus. Hum Hered. 1999;49:159-68.

47. Lehtovirta M, Kaprio J, Forsblom C, Eriksson J, Tuomilehto J, Groop L. Insulin sensitivity and insulin secretion in monozygotic and dizygotic twins. Diabetologia. 2000;43:285-93.

48. Lin H-F, Boden-Albala B, Juo S, Park N, RundekT, Sacco RL. Heritabilities of the metabolic syndrome and its components in the Northern Manhattan Family Study. Diabetologia. 2005;48:2006-12.

49. Bellia A, Giardina E, Lauro D, Tesauro M, Di Fede G, Cusumano G, et al. "The Linosa Study": epidemiological and heritability data of the metabolic syndrome in a Caucasian genetic isolate. Nutr Metab Cardiovasc Dis. 2009:19:455-61.

50. Carmelli D, Cardon LR, Fabsitz R. Clustering of hypertension, diabetes, and obesity in adult male twins: same genes or same environments? Am J Hum Genet. 1994;55:566.

51. Haddad D, Al Madhoun A, Nizam R, Al-Mulla F. Role of caveolin-1 in diabetes and its complications. Oxid Med Cell Longev. 2020;2020:9761539.

52. Nevins AK, Thurmond DC. Caveolin-1 functions as a novel Cdc42 guanine nucleotide dissociation inhibitor in pancreatic beta-cells. J Biol Chem. 2006;281:18961-72

53. Yamamoto $M$, Toya $Y$, Schwencke $C$, Lisanti M, Myers MG, Ishikawa Y. Caveolin is an activator of insulin receptor signaling. J Biol Chem. 1998:273:26962-8.

54. Hildesheim A, Wang CP. Genetic predisposition factors and nasopharyngeal carcinoma risk: a review of epidemiological association studies, 2000-2011: Rosetta stone for NPC: genetics, viral infection, and other environmental factors. Semin Cancer Biol. 2012;22:107-16.

55. Cao H, Alston L, Ruschman J, Hegele RA. Heterozygous CAV1 frameshift mutations (MIM 601047) in patients with atypical partial lipodystrophy and hypertriglyceridemia. Lipids Health Dis. 2008;7:3. 
56. Catalán V, Gómez-Ambrosi J, Rodríguez A, Silva C, Rotellar F, Gil MJ, et al. Expression of caveolin-1 in human adipose tissue is upregulated in obesity and obesity-associated type 2 diabetes mellitus and related to inflammation. Clin Endocrinol. 2008;68:213-9.

57. Park DS, Woodman SE, Schubert W, Cohen AW, Frank PG, Chandra M, et al. Caveolin-1/3 double-knockout mice are viable, but lack both muscle and non-muscle caveolae, and develop a severe cardiomyopathic phenotype. Am J Pathol. 2002;160:2207-17.

58. Frank PG, Pavlides S, Cheung MW, Daumer K, Lisanti MP. Role of caveolin-1 in the regulation of lipoprotein metabolism. Am J Physiol Cell Physiol. 2008;295:C242-8.

59. Loos RJ, Katzmarzyk PT, Rao DC, Rice T, Leon AS, Skinner JS, et al. Genome-wide linkage scan for the metabolic syndrome in the HERITAGE Family Study. J Clin Endocrinol Metab. 2003;88:5935-43.
60. Shearman AM, Ordovas JM, Cupples LA, Schaefer EJ, Harmon MD, Shao Y, et al. Evidence for a gene influencing the TG/HDL-C ratio on chromosome 7q32.3-qter: a genome-wide scan in the Framingham study. Human Mol Genet. 2000;9:1315-20.

61. Cohen AW. Caveolin-1-deficient mice show insulin resistance and defective insulin receptor protein expression in adipose tissue. Am J Physiol Cell Physiol. 2003;285:C222-35.

62. Cohen AW. Role of caveolin and caveolae in insulin signaling and diabetes. Am J Physiol Endocrinol Metab. 2003;285:1151-60.

\section{Publisher's Note}

Springer Nature remains neutral with regard to jurisdictional claims in published maps and institutional affiliations.
Ready to submit your research? Choose BMC and benefit from:

- fast, convenient online submission

- thorough peer review by experienced researchers in your field

- rapid publication on acceptance

- support for research data, including large and complex data types

- gold Open Access which fosters wider collaboration and increased citations

- maximum visibility for your research: over $100 \mathrm{M}$ website views per year

At BMC, research is always in progress.

Learn more biomedcentral.com/submissions 